\title{
Characteristics of global health diplomacy
}

\author{
Luke Kelly \\ University of Manchester \\ 18 June 2021
}

\section{Question}

Please provide an overview of definitions and key characteristics of 'Global Health Diplomacy'. What evidence is available about the characteristics and skills of 'Global Health Diplomats' employed by states (e.g. technical and political skills, seniority etc.)?

\section{Contents}
1. Summary
2. Definitions
3. National global health strategies
4. References

The K4D helpdesk service provides brief summaries of current research, evidence, and lessons learned. Helpdesk reports are not rigorous or systematic reviews; they are intended to provide an introduction to the most important evidence related to a research question. They draw on a rapid desk-based review of published literature and consultation with subject specialists.

Helpdesk reports are commissioned by the UK Foreign, Commonwealth, \& Development Office and other Government departments, but the views and opinions expressed do not necessarily reflect those of FCDO, the UK Government, K4D or any other contributing organisation. For further information, please contact helpdesk@k4d.info. 


\section{Summary}

This rapid literature review finds that global health diplomacy (GHD) is an increasingly important practice. It takes place between states, multilateral institutions and non-governmental actors. Definitions vary between scholars. States integrate health into foreign policy in different ways depending on a number of factors.

Global health diplomacy is taken to be the processes by which states and other actors seek to make global health policy. There are many definitions of global health diplomacy, which focus on different actors, processes, functions and drivers in GHD. Subjects of GHD include disease prevention; intellectual property rights; non-communicable diseases; health worker migration; health equity; and trade and investment.

This report focuses on the role and capacity of states in GHD. Analysis of states highlights:

- The increasing importance of global health diplomacy, and varied levels of state capacity.

- The factors shaping national health policies.

- The institutional arrangements and skills needed to link health and foreign policies.

- The importance of training for health diplomats.

Aside from states, multilateral forums, intergovernmental institutions, non-governmental organisations (NGOs), private companies, and public-private partnerships are also important actors.

\section{Key issues identified in the literature on GHD include:}

- The number of actors involved. All agree that the arena for health diplomacy includes a large number of actors, including states, intergovernmental organisations, private companies, public-private partnerships and non-governmental organisations.

Engagement with a wide range of stakeholders and informal diplomacy at global meetings and forums is therefore required.

- While the increasing role of multilateral diplomacy, and global agreements such as the UN's sustainable development goals (SDGs) is noted, the importance of state actors and national interests is emphasised by many authors.

- The sometimes divergent interests of the countries in the 'global north' and 'global south' is a common theme (e.g. disputes over access to pharmaceuticals/property rights).

- Health issues cross policy divides. Health diplomacy requires co-ordinating health, economic, security and other interests in national and international policy formation. This is shaped by institutional design, the ideas and norms behind policy making, and training of staff.

- How health is framed and mobilised in foreign policy can vary: e.g. health security; social epidemiology; social determinants of health, etc. These frames derive from a number of sources including national institutions (e.g. the role given to health), national political priorities, and the nature of particular health issues.

- Authors argue that more training in health diplomacy is required for both foreign affairs specialists and health specialists. 
The practice of GHD varies from actor to actor. States that train diplomats in health issues, and health specialists in diplomacy and global health, are likely to have more effective policies. The nature of a state's global health policies is shaped by its domestic interests and actors.

Several trends have been identified, including the increasing importance of global health diplomacy, the increasing number of actors in the field, and the lack of specialised training for GHD. In recent years, there has been a turn away from global and multilateral conceptions of health diplomacy towards more nationalist ones.

The evidence found is primarily in the form of peer-reviewed articles. The evidence base is strong, and includes analysis of actors and institutions involved in global health, the nature of international cooperation, the meanings of GHD, drivers and functions of GHD and countryspecific policies. However, there is a lack of consensus on the precise definitions of key terms (e.g. GHD), and relatively little research on the effects of health attachés. There are some case studies of national health policy formation (section 3 ). The report is gender-blind and disabilityblind.

\section{Definitions}

\section{Definitions of global health diplomacy}

There is no single shared definition of global health diplomacy (GHD) (Almeida, 2020). Following a review of definitions, Almeida (2020) shows that most highlight links between health and international relations. Many are normative in advocating for the importance of health in foreign policy (Almeida, 2020). She also notes that all point to 'global health challenges' as a given, without elaborating on why some health challenges are designated this way (Almeida, 2020).

See: Table 1: Definitions of global health diplomacy or health diplomacy, Source: Almeida (2020, pp. 3-4), https://oxfordre.com/publichealth/view/10.1093/acrefore/9780190632366.001.0001/acrefore9780190632366-e-25

\section{Institutions and actors}

Global health diplomacy may take bilateral or multilateral forms, and may be conducted by states, civil society actors or international organisations. Global health diplomacy describes 'multi-level and multi-actor negotiation processes' involving the private sector, charities, scientists, activists and journalists as well as state diplomats (Kickbusch et al., 2007, p. 230; Ruckert et al., 2016).

The health diplomacy practised by states varies, based on a number of factors discussed below (section 3). These include the training of health and other diplomats, the interests of different ministries and domestic constituencies and national policies. There are imbalances in negotiating power between richer and poorer countries (Kickbusch et al., 2007, p. 231). States primarily negotiate through ministries of health, foreign affairs, and health attachés (discussed in section 3). They may negotiate bilaterally or multilaterally. 
International organisations such as the World Health Organization (Kickbusch et al., 2021, pp. 28-31) ${ }^{1}$ and the United Nations are important forums for GHD. 'With WHO as the directing and coordinating agency for global health, the bulk of global health diplomacy still consists of formal negotiations between States within its governing bodies, especially when the goal is to reach agreement on international instruments' (Kickbusch et al., 2021, p. 40).

Private sector actors, public private partnerships and charities are important informal actors in GHD. Industries such as pharmaceuticals or tobacco may lobby on health issues affecting them (Kickbusch et al., 2021, pp. 22-23). Of particular importance is the recent growth of publicprivate partnerships (PPPs) (Kickbusch et al., 2007). According to Almeida (2020, p. 11), PPPs "are particularly powerful in some areas, such as global health governance (under Global Health Initiatives, GHls, and other specific arrangements)". These include the Global Fund to fight HIV/AIDS, Tuberculosis, and Malaria or the GAVI Alliance. Šehovic (2019) argues that non-state actors (NSAs) are important in raising certain issues, but national states remain key in implementing solutions (e.g. drug regulations)

See: Figure 1: pyramid of global health diplomacy, Source: (M. Brown et al., 2016), http://blogs.shu.edu/ghg/files/2016/10/Fall-2016-Issue-1.pdf

\section{National global health strategies}

A state's global health diplomacy (GHD) may be based on a national health strategy. Not every state has a consistent national health strategy (Kickbusch et al., 2007). Such a strategy may involve 'mapping many activities in global health across all government sectors, establishing new mechanisms of coordination within government' (Kickbusch et al., 2007, p. 231). In particular, health and foreign affairs departments need to co-ordinate. National policies on global health are 'policies that aim to organise and co-ordinate a state's action on global health across more than one sector of public administration, as part of a coherent approach to policy development and implementation between relevant ministries involved in improving health on a global scale' (Jones et al., 2017, p. 2). They often develop at the junction of health, foreign and development policies.

Kickbusch et al (2007) give the example of Brazil, which made health a right in the constitution, and accordingly prioritised health over a free trade agreement with the US which would have made it impossible 'to assure delivery of the health services and drugs that are currently available to the population' (Kickbusch et al., 2007, p. 231). They point to co-operation between ministries on health issues.

National policies on health are shaped by the broader international environment and have changing characteristics over time (Almeida, 2020, pp. 23-24). Since the 1990s, disease and environment have been seen as threats to national security; domestic and international issues have become more linked because of globalisation; and there has been a proliferation of non-state actors. Almeida (2020) points to the role of communicable diseases, drug-resistant pathogens; non-communicable diseases linked with consumable products; and pollution and environmental changes. Almeida, (2020, p. 34) highlight vertical (established

\footnotetext{
${ }^{1}$ https://www.who.int/about/governance/world-health-assembly
} 
actors addressing more problems) and horizontal (more actors becoming involved) expansion in health diplomacy. In recent years, increased nationalism and competition between power blocs has seen a less cooperative environment for global health diplomacy, exemplified by Covid-19 vaccine nationalism (Fidler, 2020a, 2020b, 2020c).

\section{How health is integrated into foreign policy agendas}

Foreign policies relating to health may be oriented in several ways. State-centric health diplomacy is focused on domestic needs. Alternative conceptions of 'global health diplomacy' focus on global issues and rights to health, such as those outlined in the UN's sustainable development goals. State-centric health diplomacy dominates the literature (Gagnon \& Labonté, 2013).

Several drivers have been posited for national health policies (Fidler, 2009). Labonté \& Gagnon (2010) advance that six frames can be used to conceptualise health as a foreign policy issue (see also Almeida, 2020, p. 25):

- Security

- Development

- Global public goods

- Trade

- Human rights

- Ethical/moral reasoning

Based on analysis of Swiss, Swedish, Norwegian and WHO policies, and a joint declaration by Norway, France, Brazil, Indonesia, Senegal, South Africa and Thailand, they argue that security and trade are the most potent frames (Labonté \& Gagnon, 2010).

Ruckert et al. (2021, p. 4) propose a heuristic device to study the integration of health in foreign policy, based on 3 dimensions:

- Features of institutions and the interest various actors represent in GHD, including 'the role of institutional leadership; the way in which institutions are designed to govern global health diplomacy practices; and organisational and other interests driving GHD practices.'

- The ideational environment in which GHD operates, and which 'influences how specific ideas are received'.

- Issue characteristics of the specific health concern entering foreign policy, such as issue severity, and whether it also has effects beyond the health sector (e.g. economic effects).

They analyse the GHD policies of Brazil, Mexico, Chile and Canada on these dimensions:

\section{- Institutional design}

In Brazil, Mexico, Canada and Chile, the role of GHD is shared between health and foreign affairs ministries, with foreign affairs ministries taking the lead in negotiations and health ministries providing health expertise. 
Coordination between different sectors of government is also important in shaping how health concerns are framed in foreign policy agendas. Interviews with Mexican health officials suggest that when intersectoral coordination is led by the foreign affairs ministry, it can prioritise economic and security issues. Health issues make it onto the foreign policy agenda more easily if there is trust between sectors and each sector can identify benefits. Brazil had a formal mechanism for coordination on health and foreign policy, which Ruckert et al. (2021) say may be a reason for its successful placement of health issues in foreign policy.

Informal connections and networks are also important factors. Connections with civil society organisations can bring specific issues to government attention, such as HIV/AIDS campaigns in Brazil and their role in prompting the country's international policy for generic drugs.

Training is identified as an important factor. This includes both training diplomats in health issues, and health professionals in diplomatic practice. Brazil's diplomatic school includes a course on health issues. Such training is not found in every country.

The interests of different ministries also have a bearing on how health is translated into foreign policy. Foreign ministries may prioritise health issues with a security dimension, for example.

The role of private sector lobbyists is evident in many cases. For instance, tobacco companies may lobby against the implementation of international commitments to reduce tobacco consumption.

\section{- $\quad$ The ideational environment}

It is argued that the norms and ideas shaping policymaking can make a government more or less likely to support health issues. For instance, in Brazil access to medicines was an important domestic issue, which may have made it easier for the government to promote it overseas, under the left-wing administration of President Lula. Such causes can be helped or hindered by domestic coalitions, including NGOs.

Health diplomacy can also help build a country's international reputation and build relationships with other countries.

\section{- Issue-specific characteristics}

How an issue affects a particular state, or is perceived, plays an important role in how it is acted upon. For instance, interviewees report that framing a health issue as a security issue can help it onto the foreign policy agenda. High-income countries often focus on combatting communicable rather than non-communicable diseases in low- and middle-income countries, in order to contain the former and protect themselves.

\section{Types of diplomatic action}

GHD can be categorised by the constellation of actors involved. It can be divided into '(1) core diplomacy, formal negotiations between and among nations; (2) multistakeholder diplomacy, negotiations between or among nations and other actors, not necessarily intended to lead to binding agreements; and (3) informal diplomacy, interactions between international public health 
actors and their counterparts in the field, including host country officials, nongovernmental organizations, private-sector companies, and the public' (Katz et al., 2011).

In discussing the role of health in foreign policy, Fidler (2009) identifies several issues:

- Health issues often bridge policy divides (e.g. health approaches focused on 'social determinants' require economic action);

- Health issues are susceptible to issue linkage: foreign policy actors may link health to issues such as security; or progress on negotiations on one issue may be linked to other issues (e.g. trade and health). For example, 'Indonesia, supported by other developing countries and NGOs, has linked progress on sharing virus samples for purposes of global surveillance with development of a new system of sharing the benefits, particularly influenza vaccines, produced from the global exchange and exploitation of virus samples' (Fidler, 2009, p. 21).

- Health's elasticity as issue: it is prominent in crisis, but does not always feature highly on the agenda (e.g. tropical diseases are seen as neglected by developed countries).

The number of institutions involved in global health means that forum shifting is often employed. This describes when 'states and non-state actors attempt to move an issue from one political or diplomatic forum to one more favourable to their interests' (Fidler, 2009, p. 21). As an example, developed states shifted the focus of intellectual property rights from the World Intellectual Property Organization (WIPO) to the World Trade Organisation (WTO) while less developed countries and NGOs have sought to raise issues related to pharmaceutical access and intellectual property at UN human rights forums and WHO rather than the WTO (Fidler, 2009, p.21).

It can also be categorised by the type of engagement. There may be a tension between the advancement of states' national interest, and goals advanced for the global community such as the UN's sustainable development goals (Kickbusch et al., 2021, p. 37). States' policies will also be shaped by their understandings of health (e.g. a focus on social medicine, human rights or biomedicine). Each state's health policies will be shaped by a particular mix of security, economic and strategic reasoning.

See: Table 2: Categories of health issue and types of response, Source: Almeida (2020, pp. 34-35), https://oxfordre.com/publichealth/view/10.1093/acrefore/9780190632366.001.0001/acrefore9780190632366-e-25

\section{Examples of strategies}

The literature outlines several states global health strategies, and provides analysis of the drivers behind some of these. The US, Germany and the EU all have global health strategies (Šehovic', 2019). The US National Security Strategy of 2010 highlights three areas for strategic health diplomacy: disease prevalence; treatment potential; and (geostrategic) value of affected areas in order to weigh an eventual response (Šehovic', 2019). 
Analysis of the UK's 'Health is Global: a UK Government Strategy 2008-2013' was conducted using document analysis and interviews. It found the drivers of the strategy to be (Gagnon \& Labonté, 2013):

- Self-interest in protecting security and economic interests;

- Enhancing the UK's reputation;

- A focus on global health to help others (this was found to be not as strong a driver).

Gagnon and Labonté (2013) also point to the agenda to make government more coherent through a 'whole of government approach', the perception of globalisation (e.g. the threat of SARS in 2003) and the role of civil society and policy experts. The policy drew on the US 'Health is Global' policy, and the collaboration between the UK's Nuffield Trust and the US American Association of Academic Health Centres. The role of individuals such as ministers, or the Department of Health's Dr Nick Banatvala, who had both bureaucratic and medical expertise, is also noted. It emphasises that the most influential figures tended to be 'politicians or senior public servants, and second, they encompass both health and international relations expertise through formal training and/or education or a combination of the two' (Gagnon and Labonté, 2013, p. 15).

Ministries representing trade, industry and foreign affairs had more influence than those for health and development (Gagnon and Labonté, 2013), meaning the policy prioritised health issues related to security and trade over the social determinants of health or health as a human right. However, the process of collaboration and discussion on the policy was described as useful, but time-consuming and involving significant compromise.

\section{A comparison of the health policies of China and the US in Africa reveals several differences and similarities (Killeen et al., 2018):}

- The US is more focused on vertical health diplomacy (disease-specific), whereas China is more focused on horizontal assistance (strengthening health systems with in-kind aid).

- Both countries prefer to give aid bilaterally rather than through multilateral fora.

China's diplomacy involves health priorities being defined by recipient states, with few explicit political and economic conditions (Killeen et al., 2018). However, benefits for China include expanded markets for its health products and support at the UN (Youde, 2010). China sends medical professionals, provides training and builds facilities. Typically, the costs of Chinese medical teams are borne by the host country, although China may pay for the poorer countries (Killeen et al., 2018).

The Foreign Policy and Global Health Initiative (FPGHI) is a network of South Africa, Senegal, France, Norway, Indonesia, Thailand and Brazil that promotes health topics internationally. ${ }^{2}$ It works as a network among representatives of its member states (between attaches, civil servants and ministers). It aims to set agendas at the World Health Assembly in Geneva and the UN General Assembly in New York. It issues communiqués.

\footnotetext{
2 https://www.diplomatie.gouv.fr/en/french-foreign-policy/development-assistance/prioritysectors/health/news/article/foreign-policy-and-global-health-initiative-22-08-19
} 
There is relatively little analysis of the FPGHI, but several features have been identified (Sandberg et al, 2016):

- It works as 'a trust-, confidence-, and consensus-builder among the seven member countries, where they seemed to become more sensitive to each other's political positions' (p. 85).

- As the forum includes countries from the 'global North' and the 'global South', the forum enables discussion of disputes that are likely to be mirrored at a global level (e.g. pharmaceutical intellectual property) and the formulation of compromise positions.

- Member countries can convince their respective regions of particular positions.

- Membership in the forum leads states to make more coordinated health foreign policy arrangements domestically.

\section{Characteristics and skills of diplomats}

\section{Health attachés}

Health attachés have been identified as a key role in global health diplomacy (M. D. Brown et al., 2018). However, Brown notes that 'there is little research assessing the functions and impact of health attachés' (M. D. Brown et al., 2014).

As of 2012, there were relatively few health attachés representing the United States (7), or representing other countries to the United States (5) (M. D. Brown et al., 2018). Some of the diplomats identified by a study of health attachés in the US (representing the US or representing other countries to the US) in fact worked primarily as medical practitioners for embassy staff. Most of the health attachés identified did not work as part of health sections, instead being part of commercial, science, economic or other departments. None were trained as health attachés ( $\mathrm{M}$. D. Brown et al., 2018).

In the US, the Department of Health and Human Services (HHS), Office of Global Affairs (OGA) appoints health attachés. It consults other agencies in the selection of new health attachés (M. D. Brown et al., 2014, 2018). US health attachés must work with the U.S. government, multinational organizations, non-state actors and the host country government (M. D. Brown et al., 2014). The actors they work with may have either a counterpart relationship (formalised by a signed agreement between states) or a more informal stakeholder relationship (M. D. Brown et al., 2014).

\section{Skills and expertise}

Health diplomacy is based on both health and foreign policy expertise. Therefore, 'effective global health diplomacy requires coordinated work by experts from various disciplines who have different sets of skills, especially experts from the fields of foreign policy and public health' (Kickbusch et al., 2021, p. 153).

The integration of health and foreign policy expertise is not always achieved in practice and 'research in Canada shows that barriers to integrating health into foreign policy decision-making processes include health actors' lack of diplomatic expertise (eg, knowledge of international law, negotiation skills) and diplomatic actors' lack of health expertise (eg, knowledge of health impacts of other policies, health systems)' (Jones et al., 2017, p. 2). Health experts do not always 
have diplomatic skills or expertise and calls for more professional development (M. Brown et al., 2016; Katz et al., 2011).

A study of American health attachés' views identified the need for more training a career path for those practising global health diplomacy. The areas where training would help are: diplomacy and negotiation, applied science, and cross-cultural competency. Health diplomacy was seen as a growing but under-resourced field (M. D. Brown et al., 2018).

Some of the skills of health diplomats overlap with those of traditional diplomats. For instance, relationship building is found to be particularly important in multi-stakeholder diplomacy. It can be helpful where many meetings, workshops and receptions provide opportunities for information gathering and informal diplomacy (Kickbusch et al., 2021, p. 41).

Kickbusch et al (2007) also note several capacity building projects in global health diplomacy:

- Switzerland's exchange programme for the heads of departments of OECD countries' international health departments.

- Brazil's cooperation on GHD with other Latin American and Lusophone countries in Africa. There is also dialogue between the Ministry of Health and the Brazilian School of Diplomacy to build GHD capacity

- The Global Health Centre at the Graduate Institute of International Studies in Geneva has been supported by the Swiss Federal Office for Public Health, and includes training on $\mathrm{GHD} .^{3}$

- 'Since 2007, South Africa, in conjunction with the Graduate Institute of International Relations in Geneva, has included health/AIDS diplomacy as part of its diplomatic training' (Šehovic', 2019).

\section{References}

Almeida, C. (2020). Global Health Diplomacy: A Theoretical and Analytical Review. In C. Almeida, Oxford Research Encyclopedia of Global Public Health. Oxford University Press. https://doi.org/10.1093/acrefore/9780190632366.013.25

Brown, M., Bergman, J., Mackey, T., Eichbaum, Q., McDougal, L., \& Novotny, T. (2016). Mapping Foreign Affairs and Global Public Health Competencies: Towards a Competency Model for Global Health Diplomacy. Global Health Governance, X(2). http://blogs.shu.edu/ghg/files/2016/10/Fall-2016-Issue-1.pdf

Brown, M. D., Bergmann, J. N., Novotny, T. E., \& Mackey, T. K. (2018). Applied global health diplomacy: Profile of health diplomats accredited to the UNITED STATES and foreign governments. Globalization and Health, 14. https://doi.org/10.1186/s12992-017-0316-7

Brown, M. D., Mackey, T. K., Shapiro, C. N., Kolker, J., \& Novotny, T. E. (2014). Bridging Public Health and Foreign Affairs. Science \& Diplomacy.

https://www.sciencediplomacy.org/article/2014/bridging-public-health-and-foreign-affairs

${ }^{3}$ https://www.graduateinstitute.ch/globalhealth 
Fidler, D. P. (2009). Health in foreign policy: An analytical overview. Canadian Foreign Policy Journal, 15(3), 11-29. https://doi.org/10.1080/11926422.2009.9673489

Fidler, D. P. (2020). Vaccine nationalism's politics. Science, 369(6505), 749-749. https://doi.org/10.1126/science.abe2275

Fidler, D. P. (2020). Africa, COVID-19, and International Law: From Hegemonic Priority to the Geopolitical Periphery? In Z. Yihdego, M. G. Desta, \& M. B. Hailu (Eds.), Ethiopian Yearbook of International Law 2019 (pp. 31-48). Springer International Publishing. https://doi.org/10.1007/978-3-030-55912-0_3

Fidler, D. P. (2020). The covid-19 Pandemic, Geopolitics, and International Law. Journal of International Humanitarian Legal Studies, 11(2), 237-248. https://doi.org/10.1163/18781527-bja10010

Gagnon, M. L., \& Labonté, R. (2013). Understanding how and why health is integrated into foreign policy-A case study of health is global, a UK Government Strategy 2008-2013. Globalization and Health, 9(1), 24. https://doi.org/10.1186/1744-8603-9-24

Jones, C. M., Clavier, C., \& Potvin, L. (2017). Are national policies on global health in fact national policies on global health governance? A comparison of policy designs from Norway and Switzerland. BMJ Global Health, 2(2), e000120. https://doi.org/10.1136/bmjgh-2016-000120

Katz, R., Kornblet, S., Arnold, G., Lief, E., \& Fischer, J. E. (2011). Defining Health Diplomacy: Changing Demands in the Era of Globalization. The Milbank Quarterly, 89(3), 503-523. https://doi.org/10.1111/j.1468-0009.2011.00637.x

Kickbusch, I., Silberschmidt, G., \& Buss, P. (2007). Global health diplomacy: The need for new perspectives, strategic approaches and skills in global health. Bulletin of the World Health Organization, 85, 230-232. https://doi.org/10.1590/S0042-96862007000300018

Kickbusch, I., Nikogosian, H., Kazatchkine, M., \& Kökény, M. (2021). A GUIDE TO GLOBAL HEALTH DIPLOMACY. Global Health Centre. https://www.graduateinstitute.ch/sites/internet/files/2021-02/GHC-Guide.pdf

Killeen, O. J., Davis, A., Tucker, J. D., \& Mason Meier, B. (2018). Chinese Global Health Diplomacy in Africa: Opportunities and Challenges. Global Health Governance: The Scholarly Journal for the New Health Security Paradigm, 12(2), 4-29. https://www.ncbi.nlm.nih.gov/pmc/articles/PMC6447313/

Labonté, R., \& Gagnon, M. L. (2010). Framing health and foreign policy: Lessons for global health diplomacy. Globalization and Health, 6(1), 14. https://doi.org/10.1186/1744-8603$6-14$

Ruckert, A., Almeida, C., Ramírez, J., Guerra, G., Salgado de Snyder, V. N., Orozco, E., Alvarenga, A. A., Nassim de Saboya, A., Martins dos Santos, R., Sepúlveda, D., Rivera Vivian, E. del C., Santos, M. D. S., Doriani, K., \& Labonté, R. (2021). Global Health Diplomacy (GHD) and the integration of health into foreign policy: Towards a conceptual approach. Global Public Health, 1-14. https://doi.org/10.1080/17441692.2021.1900318 
Ruckert, A., Labonté, R., Lencucha, R., Runnels, V., \& Gagnon, M. (2016). Global health diplomacy: A critical review of the literature. Social Science \& Medicine, 155, 61-72. https://doi.org/10.1016/j.socscimed.2016.03.004

Sandberg, K. I., Faid, M., and Andresen, S., State Agency and Global Health Governance: The Foreign Policy and Global Health Initiative. Global Health Governance, X(2). http://blogs.shu.edu/ghg/files/2016/10/Fall-2016-Issue-1.pdf

Šehovic', A. B. (2019). Health diplomacy: For whom? By whom? For what? Regions and Cohesion, 9(1), 161-176. https://doi.org/10.3167/reco.2019.090110

Youde, J. (2010). China's Health Diplomacy in Africa. China: An International Journal, 08(01), 151-163. https://doi.org/10.1142/S0219747210000099

\section{Acknowledgements}

We thank the following experts who voluntarily provided suggestions for relevant literature or other advice to the author to support the preparation of this report. The content of the report does not necessarily reflect the opinions of any of the experts consulted.

- David P. Fidler, Council on Foreign Relations

- Matthew Brown, US Department of Health and Foreign Services

\section{Suggested citation}

Kelly, L. (2021). Characteristics of global health diplomacy. K4D Helpdesk Report. Institute of Development Studies. DOI: 10.19088/K4D.2021.092

\section{About this report}

This report is based on six days of desk-based research. The K4D research helpdesk provides rapid syntheses of a selection of recent relevant literature and international expert thinking in response to specific questions relating to international development. For any enquiries, contact helpdesk@k4d.info.

K4D services are provided by a consortium of leading organisations working in international development, led by the Institute of Development Studies (IDS), with the Education Development Trust, Itad, University of Leeds Nuffield Centre for International Health and Development, Liverpool School of Tropical Medicine (LSTM), University of Birmingham International Development Department (IDD) and the University of Manchester Humanitarian and Conflict Response Institute (HCRI).

This report was prepared for the UK Government's Foreign, Commonwealth \& Development Office (FCDO) and its partners in support of pro-poor programmes. Except where otherwise stated, it is licensed for non-commercial purposes under the terms of the Open Government Licence v3.0. K4D cannot be held responsible for errors or any consequences arising from the use of information contained in this report. Any views and opinions expressed do not necessarily reflect those of FCDO, K4D or any other contributing organisation.

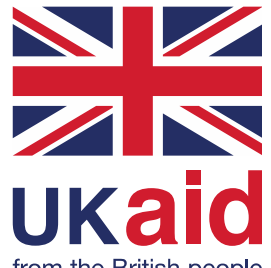

(C) Crown copyright 2021. 